\title{
Influence of Self-Sacrificial Leadership on the Pro-Organizational Unethical Behavior of Employees: A Moderated Mediating Model
}

\author{
Jianchun Yang' \\ Hongming $\mathrm{Wei}^{2}$ \\ Ying $\mathrm{Wu}^{2}$
}

'Business Administration, Guizhou University of Finance and Economics, the Guizhou Key Laboratory of Big Data Statistical Analysis, Guiyang, Guizhou, 550025, People's Republic of China; ${ }^{2}$ Business Administration, Guizhou University of Finance and Economics, Guiyang, Guizhou, 550025, People's Republic of China
Correspondence: Jianchun Yang Email 772957289@qq.com
Purpose: Based on the theory of social identity, this study focuses on the influence mechanism of self-sacrificing leadership on employees' pro-organization unethical behaviors, as well as the moderating effect of power distance and the mediating effect of organizational identity between self-sacrificing leadership and employees' pro-organization unethical behaviors.

Methods: This work surveyed 286 employees in 12 companies in Guizhou province to test the research hypothesis model. Statistical analysis methods were used for data analysis.

Results: The results reveal that self-sacrificial leadership has an indirect positive influence on unethical pro-organizational behavior of employees by positively influencing organizational identification. The higher the power distance of employees, the weaker the positive correlation between self-sacrificing leaders and organizational identity, and the lower the power distance of employees, the stronger the positive correlation between self-sacrificing leaders and organizational identity.

Conclusion: This study reveals the influence mechanism of self-sacrificing leadership on employees' pro-organization non-ethical behaviors from a new perspective and confirms the effects of power distance and organizational identity on creative performance. Unethical behavior under the cloak of "pro-organization" has a potential destructive effect on stakeholders, organizations and even the whole society. It is of great practical significance to identify its influencing factors and effectively avoid them.

Keywords: unethical pro-organizational behavior, self-sacrificial leadership, organizational identification, power distance, the theory of social identity

\section{Introduction}

In recent years, various business scandals such as Luckin Coffee's financial data fraud, GlaxoSmithKline's commercial bribery, Volkswagen exhaust valves, and the Sanlu melamine incident have been endless, which have caused a bad impact on all sectors of society and the development of enterprises. "The dike of thousands of feet collapsed with the den of ants", the various crises encountered by the enterprises are closely related to the unethical behavior of their internal employees. Based on this, the research focus of domestic and foreign scholars for a considerable period of time is to explore the causes of unethical behavior of employees. Previous studies have believed that the purpose of employees taking unethical behavior is to seek personal gain and to retaliate against colleagues or organizations. ${ }^{1}$ However, recent study by Umphress and others have found that 
protecting the interests of its members or organizations may also be the reason why employees take unethical behaviors, such as falsely reporting company performance to obtain more investment, concealing product defects to reduce company losses, et. ${ }^{2}$ This type of behavior is called unethical pro-organizational behavior by researchers. In addition, because unethical pro-organizational behavior is dressed in a "pro-organizational" cloak, it is often ignored, acquiesced and even encouraged by organizations.But over time, unethical pro-organizational behavior may damage the company's long-term interests and reputation. ${ }^{3}$ Therefore, identifying the influencing factors of the unethical pro-organizational behavior of employees and effectively avoiding it has important research significance.

A systematic review of previous literature found that leadership behaviors such as transactional leadership, ${ }^{4}$ inclusive leadership, ${ }^{5}$ ethical leadership ${ }^{6}$ and paternalistic leadership ${ }^{7}$ have proven to have a significant impact on the unethical pro-organizational behavior of employees, but the relationship between self-sacrificing leaders and it has received little attention. In addition, according to Yang's previous research, as a leadership behavior of "abandoning the individual and achieving the greater self", self-sacrificing leadership has been proven to significantly reduce the unethical pro-organizational behaviors of employees, and the positive relationship between self-sacrificial leadership and unethical pro-organizational behavior was stronger when collectivism was higher. ${ }^{8}$ However, under different perspectives whether it can effectively control the unethical pro-organizational behavior that have a certain commonality is unknown. Because through the role model of self-sacrificing leadership, employees may also sacrifice themselves or even other social groups (immoral) to protect the interests of the organization.

In summary, this article first explores the influence of self-sacrificing leadership on the unethical proorganizational behavior of employees. Secondly, the selfsacrificing leadership cares about the needs of employees, pay attention to the growth of employees, and are able to sacrifice themselves for the benefit of the organization. These behaviors help improve the self-esteem, sense of belonging and psychological security of employees. According to social identity theory, self-esteem, sense of belonging and psychological security play an important role in the construction of organizational identity. Organizational identity is defined as the perception of consistency between individuals and organizations. ${ }^{9}$ In addition, the previous empirical literature found that the higher the degree of employee identification with the organization, the more inclined to engage in the unethical pro-organizational behavior. ${ }^{6}$ So can organizational identity be used as a bridge to connect the relationship between self-sacrificing leadership and the unethical proorganizational behavior of employees? Therefore, this paper further explores the mediating role of organizational identity between the two, in order to further expand the internal mechanism between self-sacrificing leadership and unethical pro-organizational behavior of employee.

Finally, does self-sacrificing leadership definitely lead to organizational identity? Testing the effectiveness of leadership in the Chinese context should not ignore the influence of traditional culture. As one of the most important local cultural value variables, power distance refers to the degree to which individuals accept the unequal distribution of power in organizations. ${ }^{10}$ Compared with employees with high power distance, employees with low power distance obey equality. They believe that they are different from the leader in the division of labor, but there is no obvious difference in status. Obviously, they are more compatible with self-sacrificing leadership in terms of values. ${ }^{11}$ Therefore, this article finally discusses the moderating effect of power distance on the relationship between self-sacrificing leadership and organizational identity.

\section{Theoretical Overview and Research Hypotheses Self-Sacrificial Leadership and Pro-Organizational Unethical Behavior of Employees}

Self-sacrificial leadership is a kind of leadership behavior that does not afraid of risks, does not want privileges, and does not care about the rewards in order to achieve the interests and goals of the organization. ${ }^{12}$ Existing studies, especially on effectiveness results, have shown that selfsacrificial leadership positively affects creativity, ${ }^{13}$ task performance $^{14}$ and organizational citizenship behavior, ${ }^{14}$ and negatively affects relationship conflict, process conflict $^{15}$ and counterproductive behavior. ${ }^{8}$ Proorganizational unethical behavior refers to those behaviors that are intended to promote the effective functioning of an organization or its members but are contrary to social norms, moral standards and laws and regulations. ${ }^{2}$ Proorganizational unethical behavior has both "pro- 
organizational" and "unethical" characteristics. Umphress et al also put forward three conditions to define proorganizational unethical behavior: first, pro-organizational unethical behavior must be intentional, and unintentional behavior such as errors, mistakes and negligence cannot be taken into account; Second, whose actual result is against the original intention (pro-organization) cannot be defined as pro-organization unethical behavior; Third, non-ethical behavior that simply seeks private profit does not belong to the unethical behavior of pro-organization. A systematic review of the existing literature reveals that domestic and foreign scholars not only focused on the connotation definition, but also made the formation of pro-organizational unethical behavior a hot topic of concern. ${ }^{2}$ Proorganizational unethical behavior is mainly caused by individual factors and situational factors.

The personal factors are mainly related to organizational identity, ${ }^{6}$ organizational commitment ${ }^{16}$ and psychological entitlement, ${ }^{17}$ among others. The study confirmed that all four of these variables positively influence pro-organizational unethical behavior. Situational factors mainly include high performance requirements, ${ }^{18}$ differential leadership, ${ }^{3}$ transactional leadership, ${ }^{4}$ inclusive leadership, ${ }^{5}$ ethical leadership, ${ }^{6}$ and paternalistic leadership. ${ }^{7}$ Except for the inverted U-shaped relationship between ethical leadership and pro-organizational unethical behavior, the other variables are mostly positively correlated with pro-organizational unethical behavior. In the above-mentioned relationships, in terms of the mediating mechanism, most previous studies have discussed the mediating effect of moral disengagement ${ }^{18,19}$ and organizational identity; ${ }^{6}$ regarding the moderating mechanisms, more studies have investigated the moderating effects of traditionality, ${ }^{7}$ collectivism, ${ }^{3}$ moral identity, ${ }^{16,19}$ and trait regulation focus. ${ }^{6}$ Thus, reasoning self-sacrificial leadership may also be used as an antecedent variable. First of all, self-sacrificial leaders essentially altruistic, try their best to meet the growth needs and development environment of employees, and are willing to sacrifice personal interests such as remuneration and privileges for the benefit and well-being of employees. As a result, employees may find ways to engage in behaviors that benefit the organization but may actually be unethical to give back to their leadership as the agent of the organization. Secondly, self-sacrificing leaders are virtuous and have the courage to take responsibility, which can effectively dispel employees' worries about the possible adverse consequences of pro- organization unethical behavior. ${ }^{20}$ In a secure psychological atmosphere, employees are more brave to practice pro-organizational non-ethical behavior. Finally, selfsacrificing leadership and pro-organizational unethical behavior are in perfect match with each other in safeguarding the interests of the organization, so employees are more likely to be motivated to engage in proorganizational unethical behavior. In conclusion, the following hypotheses are proposed:

H1: Self-sacrificial leadership has a positive impact on employees' pro-organizational unethical behavior.

\section{Mediating Role of Organizational Identity}

Organizational identity is defined as the perception of consistency between individuals and organizations. ${ }^{9}$ The higher the sense of organizational identity, the higher the degree of fit between the individual and the organization, making employees have a stronger emotional commitment, sense of belonging, and sense of security to the organization; The lower the individual's identification with the organization, the less commonality he has with all aspects of the organization. ${ }^{6}$ There are two opposing academic perspectives about the effects of organizational identity: the first view holds that organizational identity plays a constructive role on employees' cognition, attitudes and behaviors, for example, Zhang and Li confirm that organizational identity positively influences organizational citizenship behaviors. ${ }^{9}$ The second view holds that organizational identity has a destructive effect on employees' cognition, attitude and behavior. For example, Li et al found that organizational identity positively affects workfamily conflict. ${ }^{21}$ Specifically, there may be a positive correlation between organizational identity and proorganizational non-ethical behavior. Because a high degree of organizational identity means that employees maintain a close relationship with the organization, and they are willing to do whatever it takes, even to the point of violating moral and ethical norms, in order for the organization to gain benefits and achieve its goals. A low level of organizational identity means that employees do not fit in with all aspects of the organization, so they do not want to make a useful contribution to the organization, not to mention failing to abide by social ethics in order to help business.

According to social identity theory, individuals mainly define themselves in organizations based on self-esteem, psychological sense of security, sense of belonging and 
work meaning. ${ }^{10}$ In other words, whether individuals identify with others or organizations depends on whether the above motivations can be achieved. Specifically, selfsacrificial leadership promotes all the above four kinds of motivation. First, self-sacrificing leaders care about the needs of their employees, focus on employee growth, and make them feel valuable and important to the organization, which in turn helps to enhance their organizational self-esteem and work meaning. Second, self-sacrificing leaders are virtuous, responsible and trustworthy, which can enhance the psychological security of employees. Finally, leaders sacrifice themselves for the benefit of the organization. Finally, leaders can sacrifice themselves for the benefit of the organization, which shows that the organization is trustworthy and hard-working, and employees are more likely to integrate into the organization and ultimately enhance their sense of belonging. ${ }^{10}$ Thus, it can be seen that self-sacrificing leaders can improve employees' organizational identity. According to existing studies, organizational identity is an important mediating variable of leadership style affecting subordinates' cognition, attitude and behavior, for example, Gao and Zhao found that organizational identity mediates the relationship between service-oriented leadership and employees' OCB. ${ }^{22}$ Following the above logic, self-sacrificial leadership may also indirectly influence employees' proorganizational unethical behavior through organizational identification. In conclusion, the following hypothesis is proposed:

$\mathrm{H} 2$ : Organizational identity mediates the relationship between self-sacrificing leaders and employees' proorganizational non-ethical behavior.

\section{Moderating Effect of Power Distance}

Power distance, as an important part of Hofstede's cultural dimension theory, refers to the extent to which a society accepts the unequal distribution of power in organizations or institutions. ${ }^{23}$ Although power distance was initially defined at the national level, domestic and foreign scholars later found that this concept also has great differences among different individuals in the same country, and confirmed that these individual differences have a direct or indirect impact on many results. For example, Zhou et al confirmed that power distance has a negative predictive effect on employee advice; ${ }^{24} \mathrm{Gu}$ confirmed that power distance has a negative moderating effect on the relationship between inclusive leadership and team psychological sense of security. ${ }^{25}$ This paper also focuses on the power distance at the individual level, which refers to the individual's acceptance of the unequal distribution of power in the organization. The higher the power distance, the higher the individual acceptance of power distribution inequality; the lower the power distance, the lower the individual acceptance of power distribution inequality. $^{23}$

According to the implicit leadership theory, employees usually compare their actual leadership with their desired ideal leadership. If the two match, then the leadership effectiveness is stronger, and vice versa. Specifically in this article, self-sacrificing leaders emphasize empowerment, which is not consistent with the value of high power distance employees obeying authority. ${ }^{26}$ High-power distance employees regard "tough" leaders as role models and are used to following orders, and are obviously unlikely to agree with the democratic exercise of power by self-sacrificial leaders, which is bound to weaken the positive impact of self-sacrificial leaders on organizational identity. On the contrary, the values of equality followed by employees with low power distance are very consistent with the concept of power sharing by self-sacrificing leaders, which is bound to strengthen the positive impact between the two. ${ }^{26}$ In summary, self-sacrificing leaders have a greater positive impact on the organizational identity of employees with low power distance. Based on the above analysis, the following assumptions are put forward:

H3: The relationship between self-sacrificing leadership and organizational identity is moderated by employee power distance, such that the positive relationship between selfsacrificial leadership and organizational identity is weaker when the degree of power distance is higher, and vice versa.

Based on the above logic, this paper constructs a mediating effect model with moderation:Self-sacrificing leaders indirectly influence employees' pro-organizational unethical behavior through organizational identity, and power distance influences the extent of this indirect effect. The higher the employee power distance, the weaker the positive impact of self-sacrificial leadership on organizational identity, and further weaken the intermediary role of organizational identity. In summary, the following assumptions are put forward:

H4: the indirect influence of self-sacrificing leaders on employees' pro-organizational non-ethical behavior through organizational identity is moderated by power 
distance. The lower the employee power distance, the stronger the mediating effect of organizational identity between the two, and vice versa.

The theoretical framework is shown in Figure 1 as below.

\section{Methods}

\section{Sample and Procedures}

Data were collected from two sources - on-The-job postgraduates of MBA and their colleagues - in two rounds, separated by one month. The purpose of data collection from two sources and two rounds was to reduce common method bias (Podsakoff et al 2003; Usman et al 2021). Moreover, data were collected from MBA postgraduates and their colleagues, because they are employees from various enterprises in Guizhou province and play a crucial role in their organization, as well as they are in close proximity to employees and managers. As such, we chose on-The-job postgraduates of MBA and their colleagues as our respondents.

From July to September 2019, the research group conducted two surveys on the above-mentioned enterprises. The first survey collected data about self-sacrificial leadership, power distance and organizational identity; a second survey was conducted a month later to collect data about unethical pro-organizational behavior of employees. The data of unethical pro-organizational behavior, selfsacrificial leadership, organizational identification and power distance were filled in by the respondents on the spot and immediately returned after completion.

The respondents belonged to 12 Guizhou Province of Chinese firms across different functional areas and different industries, including food, retail, manufacturing, finance and other industries. A total of 400 sets of questionnaires were distributed, and 286 sets of valid questionnaires were obtained after excluding invalid questionnaires. The descriptive statistics of the sample are: 143 men, accounting for
$50.0 \%$; 108 people mainly aged from 31 to 40 years old, accounting for $37.8 \%$; and 154 people whose education level is mainly bachelor's degree, accounting for $53.8 \%$.

\section{Study Measures}

The self-sacrificing leader is measured by a questionnaire developed by DeCremer et al, ${ }^{27}$ which contains five items, for example, "my supervisor will take high personal risks for the benefit of the organization", the internal consistency coefficient is 0.875 . The organizational identity is measured by a questionnaire developed by Ashforth et $\mathrm{al}^{28}$ which contains six items, for example, "I will feel unhappy if someone criticizes my company", and the internal consistency coefficient of is 0.910 . And the pro-organizational unethical behavior is measured by a questionnaire compiled by Umphress et al, ${ }^{2}$ which contains 6 items, for example, "I will exaggerate the quality of products or services to protect the interests of the company", and the internal consistency coefficient of is 0.955 . The power distance is measured by a questionnaire compiled by Farh et al, ${ }^{23}$ which contains six items, such as "supervisors should make their own decisions without consulting me", the internal consistency coefficient is 0.952 . All variables were scored by a 5-point Likert scale. Control variables were gender, age and education level.

\section{Results}

\section{Validity Analysis}

By constructing different structural equation models, this paper uses the method of confirmatory factor analysis to test the discriminant validity of each variable, and the results are shown in Table 1. Among the nested models such as four-factor model $\left(\chi^{2}=627.160, \quad d f=224, \quad \chi^{2} / d f=2.800\right.$, CFI $=0.931, \quad$ TLI $=0.922, \quad$ RMSEA $=0.079), \quad$ three-factor model a $\left(\Delta \chi^{2}=414.103, \Delta d f=3, \quad p<0.001\right)$, three-factor model $\mathrm{b}\left(\Delta \chi^{2}=754.525, \Delta d f=3, p<0.001\right)$, two-factor model

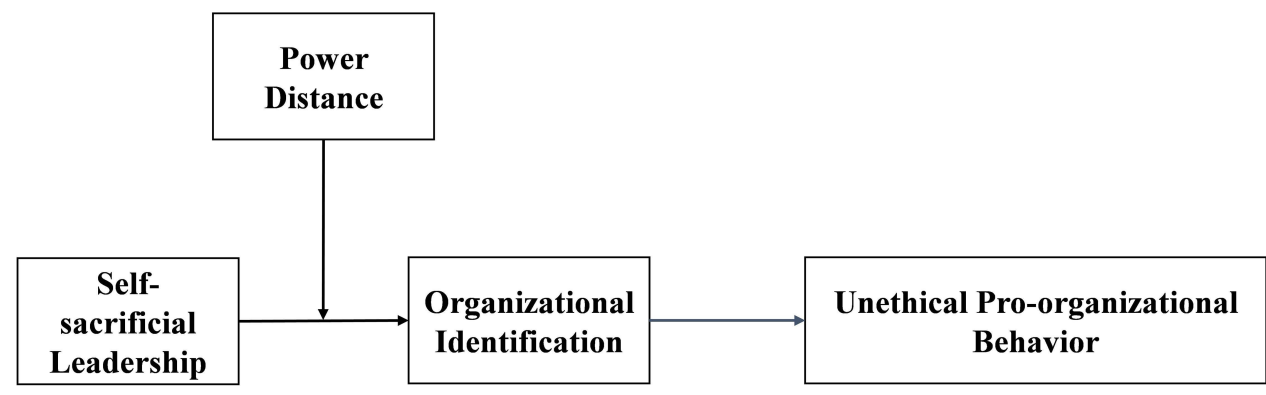

Figure I Theoretical framework. 
Table I Results of Validation Factor Analysis

\begin{tabular}{|l|c|c|c|c|c|c|c|}
\hline Model & $\chi^{2}$ & df & $\chi^{2} / \mathbf{d f}$ & $\Delta \chi^{\mathbf{2}}(\Delta \mathbf{d f})$ & CFI & TLI & RMSEA \\
\hline Four-Factor Model & 627.160 & 224 & 2.800 & & 0.931 & 0.922 & 0.079 \\
Three-Factor Model $^{\mathrm{a}}$ & 1041.263 & 227 & 4.587 & $414.103 * * *(3)$ & 0.861 & 0.845 & 0.112 \\
Three-Factor Model $^{\mathrm{b}}$ & 1381.685 & 227 & 6.087 & $754.525 * * *(3)$ & 0.803 & 0.780 & 0.134 \\
Two-Factor Model $_{\text {Single-Factor Model }}^{2813.761}$ & 3959.849 & 229 & 12.287 & $2186.601 * *(5)$ & 0.559 & 0.512 & 0.199 \\
Zero Model & 6110.462 & 253 & 17.217 & $3332.689 * *(6)$ & 0.363 & 0.300 & 0.239 \\
\hline
\end{tabular}

Notes: $*^{* *} p<0.001$; The three-factor model ${ }^{a}$ self-sacrificing leadership + organizational identity, power distance, employee pro-organizational unethical behavior. Threefactor model bself-sacrificing leadership + power distance, organizational identity, employee pro-organizational unethical behavior; Two-factor model: self-sacrificing leadership + organizational identity + power distance, employee pro-organizational unethical behavior. One-factor model: self-sacrificing leadership + organizational identity + power distance + employee pro-organizational unethical behavior. "+" indicates integration.

$\left(\Delta \chi^{2}=2186.601, \Delta d f=5, p<0.001\right)$ and single-factor model $\left(\Delta \chi^{2}=3332.689, \Delta d f=6, p<0.001\right)$, the four-factor model has the best fitting effect to the actual data, indicating that the validity of the variables involved in this paper is high.

\section{Descriptive Statistics}

The results of descriptive statistical analysis of variables in this paper are shown in Table 2. There was a significant positive correlation between self-sacrificial leadership and organizational identity $(r=0.503, p<0.01)$, and between organizational identity and pro-organizational unethical behavior $(r=0.223$, $p<0.01)$. And organizational identity had a significant positive correlation with employee pro-organizational unethical behavior $(r=0.414, p<0.01)$. But there was no significant correlation between power distance and other variables.

\section{Analysis of the Mediating Effect}

In this paper, the hierarchical regression method is adopted to test the mediating effect of organizational identity by constructing a structural equation model, and the results are shown in Table 3. According to model 4, self-sacrificial leadership has a positive effect on employees' pro-organizational unethical behavior $(\beta=0.235, p<0.001)$, and $\mathrm{H} 1$ is further supported; according to model 2 and model 5 , self-sacrificial leadership positively affects organizational identity $(\beta=0.53$, $p<0.001$ ), and organizational identity also positively affects employees' pro-organizational unethical behavior $(\beta=0.408$, $p<0.001$ ). Model 6 showed that organizational identity still positively influenced employees' pro-organizational unethical behavior $(\beta=0.395, p<0.001)$ after the inclusion of control variables, independent variables, and mediating variables. However, the positive effect of self-sacrificing leadership on employees' pro-organizational unethical behavior is no longer significant $(\beta=0.025, p>0.05)$. These show that organizational identity mediates the relationship between self-sacrificial leadership and employees' pro-organizational unethical behavior, and $\mathrm{H} 2$ is initially supported.

In order to verify the significance of the mediating effect, this paper used the non-parametric Bootstrap method to test that the indirect effect, and the results shows that the indirect effect of self-sacrificing leaders on employees' pro-organizational unethical behavior through organizational identity was 0.267 , with a $99 \%$ confidence interval (CI) of [0.156, 0.410], excluding 0 . It

Table 2 Results of Descriptive Statistical Analysis of Variables

\begin{tabular}{|c|c|c|c|c|c|c|c|c|}
\hline Variable Name & Mean & $\begin{array}{l}\text { Standard } \\
\text { Deviation }\end{array}$ & $\mathbf{I}$ & 2 & 3 & 4 & 5 & 6 \\
\hline I.Gender & 0.500 & 0.501 & & & & & & \\
\hline 2.Age & 2.213 & 1.016 & -0.100 & & & & & \\
\hline 3.Education Degree & 2.647 & 0.840 & $0.121 *$ & -0.080 & & & & \\
\hline 4.Self-Sacrificing Leadership & 4.187 & 0.654 & 0.013 & $-0.183^{* *}$ & $0.148^{*}$ & & & \\
\hline 5.Organizational Identity & 3.805 & 0.587 & -0.053 & 0.084 & 0.086 & $0.503^{* *}$ & & \\
\hline 6.Power Distance & 3.093 & 1.123 & -0.020 & -0.051 & -0.092 & -0.065 & -0.095 & \\
\hline $\begin{array}{l}\text { 7.Employee Pro-Organizational Unethical } \\
\text { Behavior }\end{array}$ & 3.873 & 0.833 & -0.056 & 0.052 & 0.061 & $0.223 * *$ & $0.414^{* *}$ & 0.099 \\
\hline
\end{tabular}

Notes: ${ }^{*} p<0.05,{ }^{*} p<0.0 \mathrm{I}$, two-tailed test. Gender: male ( 0$)$, female (I); age: 30 years old and below ( 1 ), $3 \mathrm{I}-40$ years old (2), $3 \mathrm{I}-50$ years old (3), $5 \mathrm{I}$ years old and above (4); education: high school (I), college (2), undergraduate (3), graduate (4). 
Table 3 Results of Hierarchical Regression Analysis

\begin{tabular}{|c|c|c|c|c|c|c|c|c|}
\hline \multirow[t]{2}{*}{ Variable Name } & \multicolumn{2}{|c|}{$\begin{array}{l}\text { Organizational } \\
\text { Identity }\end{array}$} & \multicolumn{4}{|c|}{$\begin{array}{l}\text { Employee Pro-Organizational Unethical } \\
\text { Behavior }\end{array}$} & \multicolumn{2}{|c|}{$\begin{array}{l}\text { Organizational } \\
\text { Identity }\end{array}$} \\
\hline & MI & M2 & M3 & M4 & M5 & M6 & M7 & M8 \\
\hline Gender & -0.056 & -0.045 & -0.060 & -0.055 & -0.037 & -0.037 & -0.046 & -0.043 \\
\hline Age & 0.086 & $0.179 *$ & 0.052 & 0.093 & 0.017 & 0.022 & $0.175^{*}$ & $0.166^{*}$ \\
\hline Education Degree & 0.100 & 0.027 & 0.073 & 0.041 & 0.032 & 0.030 & 0.023 & 0.013 \\
\hline Self-Sacrificing Leadership & & $0.533 * *$ & & $0.235^{* *}$ & & 0.025 & $0.529 * *$ & $0.519 * *$ \\
\hline Organizational Identity & & & & & $0.408 * *$ & $0.395 * *$ & & \\
\hline Power Distance & & & & & & & -0.051 & -0.008 \\
\hline Self-Sacrificing Leadership $\times$ Power Distance & & & & & & & & $-0.216 * *$ \\
\hline$R^{2}$ & 0.019 & 0.288 & 0.011 & 0.063 & 0.174 & 0.174 & 0.290 & 0.335 \\
\hline$\Delta \mathrm{R}^{2}$ & - & 0.269 & - & 0.052 & 0.163 & 0.163 & 0.279 & 0.324 \\
\hline $\mathrm{F}$ & 1.798 & $28.395 * *$ & 1.001 & $4.720^{*}$ & $14.760 * *$ & $11.800 * *$ & $22.920 * *$ & $23.396 * *$ \\
\hline
\end{tabular}

Note: $*_{p}<0.01,{ }^{* *} p<0.001$.

can be concluded that the mediating effect of organizational identity is significant, and $\mathrm{H} 2$ is further supported.

\section{Moderating Effect Analysis}

As shown in Table 3, according to model 8, the interaction between self-sacrificial leadership and power distance has a negative impact on organizational identity significantly ( $\beta=-0.216, p<0.001)$, which indicates that power distance moderates the effect of self-sacrificing leadership on organizational identity. Drawing on Aiken and West, an effect diagram of power distance moderating the relationship between self-sacrificing leadership and organizational identity was produced ${ }^{29}$ in Figure 2. The results of the simple slope analysis indicated that the higher the employee power distance, the weaker the positive relationship between selfsacrificing leadership and organizational identity $(b=0.190$, $\mathrm{t}=4.166, p<0.001)$, and the lower the power distance of employees, the stronger the positive relationship between self-sacrificial leadership and organizational identity ( $b=0.434, t=9.905, p<0.001)$. So H3 got initial support.

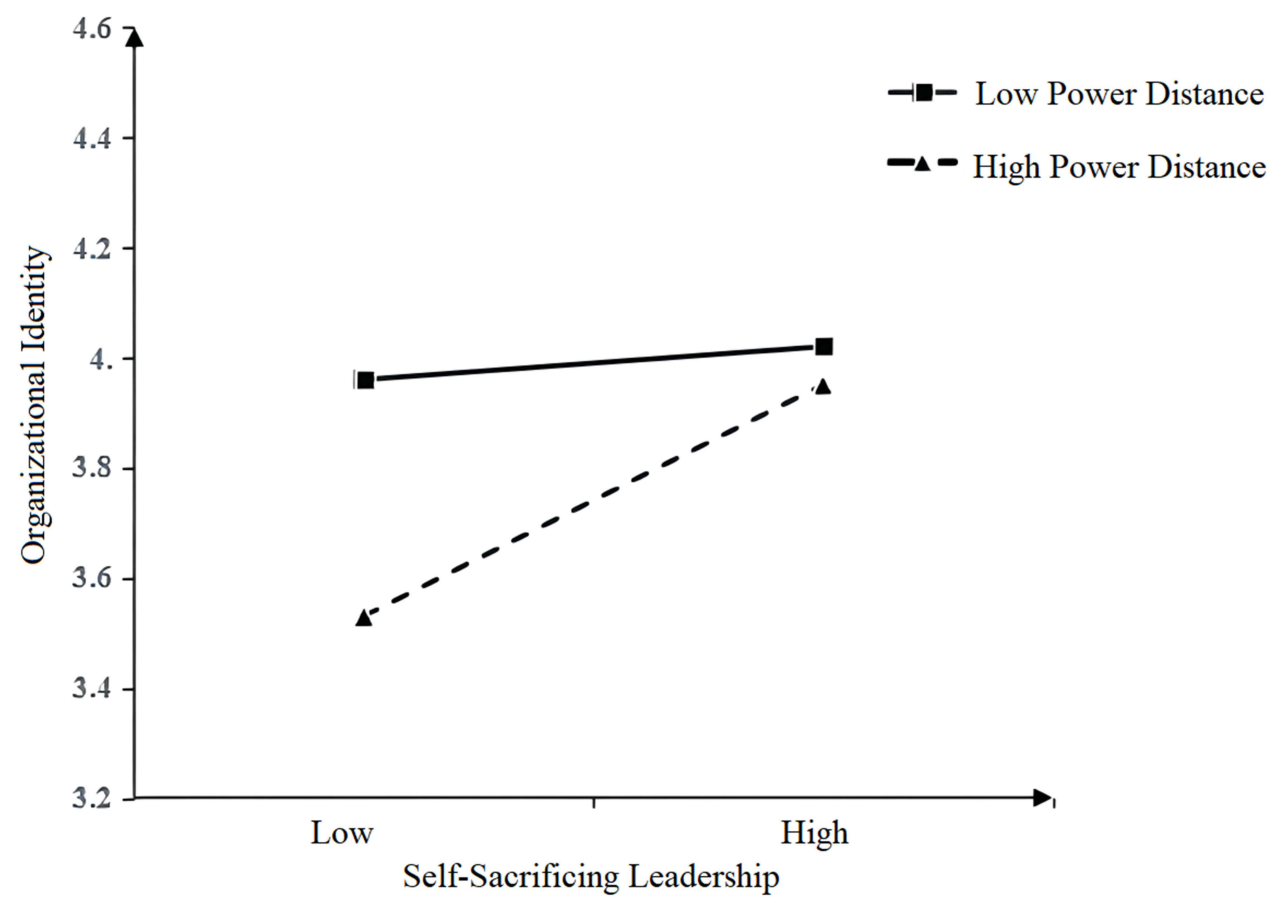

Figure 2 Moderating effect of power distance on the relationship between self-sacrificing leadership and organizational identity. 
Table 4 Results of the Total Effect Moderation Model Analysis

\begin{tabular}{|l|c|c|c|c|c|}
\hline Moderating Variables & Phase I & Phase II & Direct Effect & Indirect Effects & Total Effect \\
\hline Low Power Distance & $0.740^{* *}$ & $0.375^{* *}$ & 0.041 & $0.278^{* *}$ & $0.319^{* *}$ \\
& {$[0.594,0.91 \mathrm{I}]^{\mathrm{b}}$} & {$[0.186,0.558]^{\mathrm{b}}$} & {$[-0.169,0.249]^{\mathrm{a}}$} & {$[0.135,0.452]^{\mathrm{b}}$} & {$[0.095,0.56]^{\mathrm{b}}$} \\
High Power Distance & $0.323^{* *}$ & $0.252^{* *}$ & -0.002 & $0.08 I^{* *}$ & 0.079 \\
& {$[0.155,0.480]^{\mathrm{b}}$} & {$[0.057,0.423]^{\mathrm{b}}$} & {$[-0.16,0.137]^{\mathrm{a}}$} & {$[0.021,0.177]^{\mathrm{b}}$} & {$[-0.08 \mathrm{I}, 0.232]^{\mathrm{a}}$} \\
Difference & $-0.417^{* *}$ & -0.124 & -0.043 & $-0.196^{* *}$ & $-0.24^{*}$ \\
& {$[-0.642,-0.220]^{\mathrm{b}}$} & {$[-0.328,0.079]^{\mathrm{a}}$} & {$[-0.318,0.198]^{\mathrm{a}}$} & {$[-0.377,-0.027]^{\mathrm{b}}$} & {$[-0.497,-0.011]^{\mathrm{a}}$} \\
\hline
\end{tabular}

Notes: ${ }^{\text {a,b }}$ Indicate $95 \%$ and $99 \%$ confidence intervals, respectively. ${ }^{*} p<0.05,{ }^{*} *_{p}<0.01$.

In this paper, Bootstrap method was used for the total effect moderation model analysis by using Mplus software, and the results are shown in Table 4. The results of the first stage show that the effect of self-sacrificing leadership on organizational identity was significant in both the low power distance $(b=0.740,99 \% \mathrm{CI}=[0.594$, 0.911]) and high power distance $(b=0.323,99 \% \mathrm{CI}=$ $[0.155,0.480])$, and the difference $(b=-0.417,99 \% \mathrm{CI}=$ $[-0.642,-0.220])$ was also significant, the $\mathrm{H} 3$ was further supported. The indirect effects of self-sacrificing leaders on employees' pro-organizational non-ethical behavior through organizational identity are significant under the conditions of low power distance $(\mathrm{b}=0.278,99 \% \mathrm{CI}=$ $[0.135,0.452])$ and high power distance $(b=0.081,99 \%$ $\mathrm{CI}=[0.021,0.177])$, and the difference $(b=-0.196,99 \%$ $\mathrm{CI}=[-0.377,-0.027])$ were also significant, the $\mathrm{H} 4$ was supported.

\section{Discussion}

Based on the theory of social identity, this study reveals the influence mechanism of self-sacrificing leadership on employees' pro-organization non-ethical behaviors from a new perspective, as well as the moderating effect of power distance and the mediating effect of organizational identity. But most of current research about leadership behaviors has focused more on transactional leadership, ${ }^{4}$ inclusive leadership, ${ }^{5}$ ethical leadership, ${ }^{6}$ paternalistic leadership ${ }^{7}$ and so on, but the self-sacrificing leadership and the relationship between self-sacrificing leadership and non-ethical pro-organization behaviors have received little attention. Unethical behavior under the cloak of "proorganization" has a potential destructive effect on stakeholders, organizations and even the whole society. It is of great practical significance to identify its influencing factors and effectively avoid them.

Although the author has previously studied the relationship between the self-sacrificing leadership and unethical pro-organization behaviors of employees, the role of organizational identification and power distance has not been considered. Therefore, this study provides a new research perspective to explore the relationship between self-sacrificing leadership and unethical proorganization behaviors of employees and further enrich the internal mechanism between the two.

\section{Theoretical Contributions and Management Implications}

The theoretical implications of this paper lies in: first, it confirms the positive effect of self-sacrificing leadership on employees' pro-organizational unethical behavior. Scholars have explored the positive effects of selfsacrificing leadership on employees, such as effectively promoting employee performance, ${ }^{14}$ creativity ${ }^{13}$ and prosocial behavior, ${ }^{14}$ but their negative effects have received little attention. Different from "work performance", unethical pro-organization behaviors of employees may bring some risks, which requires self-sacrificing leadership to play a more effective role so as to better manage unethical pro-organization behaviors of employees. This paper also reveals the relationship between self-sacrificial leadership and unethical pro-organization behaviors of employees, further enriching the antecedent variables of unethical pro-organization behaviors of employees. This paper finds that employees take self-sacrificing leaders as role models, learning from their dedication spirit and engaging in non-ethical behaviors that benefit the organization and its members. This finding is also consistent with previous studies, such as paternalistic leadership has a positive impact on employees' pro-organizational unethical behavior. ${ }^{30}$

Secondly, it reveals the mediating mechanism that self-sacrificial leadership affects the employees' proorganizational non-ethical behavior. Some previous studies have shown that organizational identity has 
a positive impact on employees' pro-organizational unethical behavior, ${ }^{4}$ and other studies have confirmed that self-sacrificial leaders have a positive predictive effect on organizational identity. ${ }^{9}$ However, so far, there are no related studies to discuss the above three concepts under the same theoretical framework. According to the study of $\mathrm{Li}^{6}{ }^{6}$ the promoting mechanism of self-sacrificing leadership and the formation mechanism of proorganizational unethical behavior of employees can be explained by social identity theory. Following this logic, this paper constructs a theoretical model to confirm that organizational identity is the mediating variable between the two variables. This paper effectively reveals how self-sacrificial leadership influences unethical proorganization behaviors of employees. Although relevant scholars have found that organizational identity can be a bridge connecting self-sacrificing leadership and employee behavior, the research on organizational identity directly and effectively affects employee cognition, attitude and behavior from the same perspective is relatively weak, and scholars also strongly call for the exploration of its mediating effect. Based on this, from the perspective of social identity theory, this paper examines and confirms the internal path of self-sacrificial leadership influencing unethical pro-organization behaviors of employees through organizational identity, further enriching the mediating mechanism between them.

Thirdly, it defines the boundary conditions under which self-sacrificing leaders influence organizational identity. Power distance significantly negatively adjusts the influence of self-sacrificial leadership on organizational identity, which means that employees with low power distance are more likely to produce organizational identity in the face of self-sacrificial leadership, and vice versa. Most of the boundary condition studies on the effects of self-sacrificing leadership have discussed the influence of employee traits such as defensive focus and leadership characteristics such as leadership typicality, ${ }^{27}$ but pay little attention to employees' cultural values. This paper extends the existing results on self-sacrificing leadership and organizational identity by selecting power distance as a moderating variable for self-sacrificing leadership to influence organizational identity.

The non-ethical behavior under the guise of "proorganization" has a potential destructive effect on stakeholders, organizations and even the society as a whole, and it is of great practical significance to identify their influencing factors and effectively avoid them. First, this paper finds that self-sacrificial leaders have an indirect positive impact on employees' pro-organizational non-ethical behavior by positively affecting organizational identity, which suggests that enterprise managers should avoid employees' pro-organizational non-ethical behavior by blindly learning self-sacrificial leadership or highly identifying with the organization. Measures include spreading correct values, enhancing employees' moral awareness, strengthening ethical training, improving employees' moral sensitivity, promoting the construction of ethical rules and regulations, and restricting employees' immoral behavior. Second, this paper finds that the higher the employee power distance is, the weaker the positive relationship between selfsacrificial leadership and organizational identity is; the lower the employee power distance is, and the stronger the positive relationship between self-sacrificial leadership and organizational identity is, which suggests that enterprise managers should treat employees with different power distances differently and focus on low-powerdistance employees who are more sensitive to selfsacrificial leaders. Measures include reducing their own authoritarian image, empowering employees, and so on.

\section{Limitations and Future Research}

The limitations of the study include the following three points: first, the questionnaires in this paper were all filled out by employees, which may have the problem of common method variance, which can be further improved in combination with experimental research in the future. Second, this paper only examines the moderating effect of power distance on the relationship between self-sacrificing leadership and organizational identity; other cultural value variables such as longterm orientation could be selected in the future. Finally, this paper does not discuss the influence of selfsacrifice leadership on leaders themselves. We believe that self-sacrificing leaders may act unethically. According to the moral permission theory, the moral behavior or social approval behavior made by individuals in the past helps them accumulate moral reputation. $^{25}$ Based on this, individuals who do bad things will get permission from themselves and others. Self-sacrificing leaders will show altruistic behaviors such as caring for employees' needs and growth, and will choose to sacrifice their own personal interests for the benefit and well-being of employees. These acts of 
self-sacrificing leadership confirm oneself as a person of high moral character and moral credibility. According to the moral permission theory, self-sacrificing leaders may then make unethical behavior, which needs to be further verified by future research.

\section{Conclusions}

Based on social identity theory, this paper focuses on the influence mechanism of self-sacrificing leadership on employees' pro-organizational unethical behavior and the moderating role of power distance and the mediating role of organizational identity. The statistical analysis of 286 samples of employees from 12 enterprises in Guizhou province showed that: self-sacrificing leaders positively influence employees' pro-organizational unethical behavior indirectly through positively influencing organizational identity; the higher the power distance of employees, the weaker the positive association between self-sacrificing leaders and organizational identity, and vice versa.

\section{Ethics Statement}

The study proposals were reviewed and approved by the Academic Committee of Guizhou University of Finance and Economics, and that it was conducted in accordance with the Declaration of Helsinki. Moreover, before collecting data, the vital information about the study has been introduced to participants and we have obtained the participants' written consent who take part in the research prior to the commencement of the study.

\section{Funding}

The funding for this study is provided by National Social Science Foundation of China [Number 20BMZ128], "A study on the Mechanism and path of Rural Revitalization guided by the High-quality Development of Tourism in ethnic villages", and Guizhou Key Laboratory of Big Data Statistical Analysis (No.[2019]5103), Guiyang 550025, China.

\section{Disclosure}

The authors declare that the research was conducted in the absence of any commercial or financial/non-financial relationships that could be construed as a potential conflict of interest.

\section{References}

1. Kish-Gephart JJ, Harrison DA, Treviño LK. Bad apples, bad cases, and bad barrels: meta-analytic evidence about sources of unethical decisions at work. J Appl Psychol. 2010;95(1):1-31. doi:10.1037/a0017103

2. Umphress EE, Bingham JB, Mitchell MS. Unethical behavior in the name of the company: the moderating effect of organizational identification and positive reciprocity beliefs on unethical pro-organizational behavior. J Appl Psychol. 2010;95(4):769-780. doi:10.1037/a0019214

3. Lin YH, Cheng K. Disordered leadership and employee pro-organizational unethical behavior: from the perspective of insiders and outsiders. Manage Sci. 2017;30(3):35-50.

4. Graham KA, Ziegert JC, Capitano J. The effect of leadership style, framing, and promotion regulatory focus on unethical pro-organizational behavior. J Bus Ethics. 2015;126(3):423-436. doi:10.1007/s10551-013-1952-3

5. He B, He Q, Sarfraz M. Inclusive leadership and subordinates' prosocial rule breaking in the workplace: mediating role of self-efficacy and moderating role of employee relations climate. Psychol Res Behav Manag. 2021;14:1691-1706. doi:10.2147/PRBM.S333593

6. Li GQ. Ethical leadership, organizational identity, and employee pro-organizational non-ethical behavior: the moderating role of trait regulation focus. Sci Technol Manag. 2016;37(12):125-135.

7. Zhang YJ, Zhang PC, Zhao J. The influence of paternalistic leadership on employees' pro-organizational unethical behavior: based on moderating effect of traditionality. Nankai Manag Rev. 2017;20 (2):169-179.

8. Yang JC, Lu L, Yao N, et al. Self-sacrificial leadership and employees' unethical pro-organizational behavior: roles of identification with leaders and collectivism. Soc Behav Pers. 2020;48(2):1-12.

9. Zhang SL, Li MS. The influence of organizational ethical climate on organizational civic behavior: the mediating role of organizational identity. Manage Rev. 2013;25(11):85-94.

10. Kirkman BL, Chen G, Farh JL, et al. Individual power distance orientation and follower reactions to transformational leaders: a cross-level, cross-cultural examination. Acad Manag J. 2009;52 (4):744-764.

11. Tang HY, Long LR, Zhou RY. Humble leadership behavior and subordinate work engagement: a mediated moderating model. Manage Sci. 2015;28(3):77-89.

12. Choi Y, Yoon J. Effects of leaders' self-sacrificial behavior and competency on followers' attribution of charismatic leadership among Americans and Koreans. Curr Res Soc Psychol. 2005;11 (5):51-69.

13. Yu W, Zhang P. The effect of self-sacrificing management style on creativity of R\&D employees - an empirical analysis based on a multi-layer linear model. Res Dev Manag. 2016;28(4):97-105.

14. Li Y, Zhang WH, Long LR. Mechanisms of self-sacrificing leaders' influence on subordinates' job performance-mediating role of strategic orientation and leadership identity. J Psychol. 2015;47 (5):653-662.

15. Zhou RY, Long LR. The inhibitory mechanism of self-sacrificing leadership on team destructive conflict. J Manage. 2016;13 (9):1339-1348.

16. Wu MZ, Shen B, Sun XL. The relationship between organizational commitment and pro-organizational unethical behavior: the moderating role of moral identity. Psychol Sci. 2016;39(2):392-398.

17. Lee A, Schwarz G, Newman A, et al. Investigating when and why psychological entitlement predicts unethical pro-organizational behavior. J Bus Ethics. 2019;154(1):109-126. doi:10.1007/s10551017-3456-z

18. Chen M, Liang J. High performance requirements and pro-organizational unethical behavior: a perspective based on social cognitive theory. J Psychol. 2017;49(1):94-105. 
19. Zhao HD, Zhou J. Corporate hypocrisy, moral pushback and pro-organizational unethical behavior: moderated mediating effects. Foreign Econ Manag. 2017;39(1):15-28.

20. Li R, Zhang ZY, Tian XM. Can self-sacrificial leadership promote subordinate taking charge? The mediating role of organizational identification and the moderating role of risk aversion. J Organ Behav. 2016;37(5):758-781. doi:10.1002/job.2068

21. Li Y, Fan J, Zhao S. Organizational identification as a double-edged sword: dual effects on job satisfaction and life satisfaction. J Person Psychol. 2015;14(4):182-191. doi:10.1027/1866-5888/a000133

22. Gao ZH, Zhao C. How do servant leaders awaken their subordinates' organizational citizenship behaviors? An analysis of social identity theory. Econ Manag. 2014;36(6):147-157.

23. Farh JL, Hackett RD, Liang J. Individual-level cultural values as moderators of perceived organizational support - employee outcome relationships in China: comparing the effects of power distance and traditionality. Acad Manag J. 2007;50(3):715-729. doi:10.5465/ amj.2007.25530866

24. Zhou JT, Liao JQ. Power distance orientation and employee suggestion: the impact of perceived organizational status. Manage Sci. 2012;25(No1):35-44.
25. Gu YH. The impact of inclusive leadership on employees' innovative behavior: a mediated model of being moderated. Econ Manag. 2016;38(4):93-103.

26. Zhou RY, Long LR, He W. Self-sacrificing leadership and employee counterproductive behavior: the role of leadership identity and psychological entitlement. Forecasting. 2016;35(3):1-7.

27. Van KB, Van KD. Leader self-sacrifice and leadership effectiveness: the moderating role of leader prototypicality. J Appl Psychol. 2005;90 (1):25-37. doi:10.1037/0021-9010.90.1.25

28. Ashforth BE, Harrison SH, Corley KG. Identification in organizations: an examination of four fundamental questions. J Manage. 2008;34(3):325-374. doi:10.1177/0149206308316059

29. Aiken L, West S. Multiple Regression: Testing and Interpreting Interactions. Newbury Park, CA: Sage; 1991.

30. Wang YZ, Li Y. Study on the influence mechanism of self-sacrificing leadership on staff deviation. J Cent Univ Finance Econ. 2018; (2):109-117. doi:10.3389/fpsyg.2019.02640
Psychology Research and Behavior Management

\section{Publish your work in this journal}

Psychology Research and Behavior Management is an international, peer-reviewed, open access journal focusing on the science of psychology and its application in behavior management to develop improved outcomes in the clinical, educational, sports and business arenas. Specific topics covered in the journal include: Neuroscience, memory and decision making; Behavior modification and management; Clinical applications; Business and sports performance management; Social and developmental studies; Animal studies. The manuscript management system is completely online and includes a very quick and fair peer-review system, which is all easy to use. Visit http://www. dovepress.com/testimonials.php to read real quotes from published authors. 